\title{
Existe relação entre as estruturas cerebrais e a performance funcional de pacientes com migrânea?
}

\author{
Nicoly Machado Maciel ${ }^{1}(\mathrm{D})$, Gabriela Ferreira Carvalho ${ }^{2}$ (D) Natália Oliveira' $^{1}$ (D) Carina Ferreira Pinheiro ${ }^{1}$ (D),

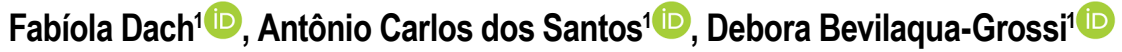

'Faculdade de Medicina de Ribeirão Preto, Universidade de São Paulo, Ribeirão Preto, SP, Brasil.

${ }^{2}$ Institute of Health Sciences, Department of Physiotherapy, University of Luebeck, Luebeck, Germany

\begin{abstract}
Introdução
Mudanças estruturais do Sistema Nervoso Central estão comumente associadas com alterações funcionais. Apesar de estar estabelecida a presença de alterações morfológicas cerebrais e a redução da performance de tarefas funcionais em pacientes com migrânea, a relação entre esses dois fatores ainda não foi verificada nessa população.
\end{abstract}

\section{Objetivo}

Avaliar a relação entre o volume cerebral e volume de lesões de substância branca com a performance funcional em tarefas locomotoras dinâmicas.

\section{Material e Métodos}

Este estudo transversal considerou 45 mulheres com migrânea. Para a avaliação cinemática, foi utilizado o sistema de captura de movimento VICON. Foram realizadas duas tarefas funcionais (caminhada com subida e caminhada com descida de degrau). As voluntárias também foram submetidas a uma avaliação encefálica por meio de ressonância magnética (RM). As imagens foram inspecionadas por neurorradiologista cegos e processadas no software Freesurfer. Este projeto foi aprovado pelo comitê de ética (processo $n^{\circ} 16210 / 2015$ ).

\section{Resultados}

Uma regressão linear múltipla foi usada para examinar a associação as variáveis morfológicas e funcionais. Na tarefa de subida de degrau, $31,2 \%$ da variação da velocidade do passo foi explicada pelo volume do cerebelo, lobo parietal e lobo temporal ( $p=0,001$ ). Já na tarefa de descida de degrau, 25,1\% da variação da velocidade do passo também foi explicada pelo volume do cerebelo, lobo parietal e lobo temporal ( $p=0,007)$. Como visto em outras doenças, essas regiões também foram correlacionadas com a função motora na migrânea. De fato, essas regiões cerebrais estão alteradas na migrânea em relação aos controles. Além disso, tais regiões tem funções relacionadas às funções motoras, confirmando nossos achados.

\section{Conclusão}

A variabilidade do movimento pode ser explicada pela variação do volume das regiões cerebrais relacionadas ao processamento do controle postural em pacientes com migrânea.

Palavras-chave: Transtornos de Enxaqueca, Fenômenos Biomecânicos, Imagem de Ressonância Magnética. 